\title{
Web Content Management Systems used by Search Engine Optimization Experts for Top Rankings in Search Engine Results Pages
}

\author{
CHRISTOS ZIAKIS $^{1, *}$, MARO VLACHOPOULOU ${ }^{2}$ \\ ${ }^{1,2}$ Department of Applied Informatics, Information Systems \& e-Business (ISeB) Laboratory \\ University of Macedonia \\ 156 Egnatia str., 54006, Thessaloniki \\ GREECE \\ * Correspondence: ziakis@uom.edu.gr; Tel.: +30 6937462999
}

\begin{abstract}
There are several Web Content Management Systems (WCMS) available that are used by web developers in order to develop and manage a website. In addition, over the last years, companies have invested in Search Engine Optimization (SEO) techniques by applying the factors used by search engines, such as Google, in order to rank amongst the first results in Search Engine Results Pages (SERPs). On-page factors such as the implementation of keywords in the title tags and the website loading time are amongst the criteria that are taken into consideration and are directly affected by the website's technology and WCMS. Following a relevant literature review, the authors conducted research amongst 6682 websites in order to identify whether and which WCMS is used by SEO experts' websites that appear in the top search results. Findings indicated that custom made websites that do not rely on widely used WCMSs appear more frequently at the top of search results, while the Drupal CMS appears quite high, despite it being used by a small number of websites across the web.
\end{abstract}

Keywords: Search Engine Optimization, SEO, WCMS, Google, Search Engine, Ranking factor, Digital Marketing

Received: March 1, 2021. Revised: September 7, 2021. Accepted: September 16, 2021. Published: September 23, 2021.

\section{Introduction}

SEO is a highly critical process which impacts the rankings of a website in search engines, such as Google [1]. Given that buyers use the internet and search engines in their everyday life in order to search for products and services, showing up at the top organic results ensures a plethora of potential clients for a company and contributes to the development and improvement of its profitability $[2,3]$. It has been proven that the successful implementation of a SEO strategy contributes towards improving product marketing and allows companies to enhance their visibility, to increase user engagement and sales revenue [4,5]. On the other hand, if a company does not manage to efficiently apply SEO techniques and to appear at the top rankings in organic search results, it then has to spend large amounts on paid campaigns for specific keywords; however, a SEO strategy is more cost effective than a paid campaign [6].

Furthermore, research shows that the Google search engine is used by $92,26 \%$ of internet users and many of these have it set as the default option while using Google Chrome [7]. It has been suggested that the factors which affect website rankings in terms of search results are classed as either on-page or off-page factors [8]. SSL certificate use, keywords use in landing pages, responsive design for mobile devices and website loading speed are all considered on-page factors, as a website with a fast-loading speed creates a positive user experience [9].

As discussed further on in the research, the aforementioned indicative factors are affected by the technology of the website. Website development can be accomplished through the use of closed-source or open-source WCMS, which are quite popular [10].

In the present article the authors aimed to study which WCMs are used by SEO experts as well as to examine whether the use of a specific CMS positively affects ranking in SERPs. The current research was conducted based upon reviewing relevant research and literature.

To be more specific, at the first stage the researchers selected 6882 SEO experts' websites which appeared in Google search results for specific keywords, based on their ranking. Initially 
180 keywords were used and the top 40 results for each of these were recorded. At the next stage, an automated search was conducted regarding the use of any of the most popular WCMS. Later on the authors presented and analyzed these findings by associating the use of the aforementioned WCMS with the impact on Google ranking.

\section{Web Content Management Systems and Search Engine Optimization}

\subsection{Web content management systems}

Web developers are currently able to use WCMSs which allow them to create a website within a short timeframe as well as to effectively manage it $[11,12]$. These systems provide publishing and digital content management tools without having to know a web programming language such as HTML or PHP [13]. Most of these are open source and provide fast and affordable development of web applications [14]. Thanks to the available WCMS, businesses are able to easily create complex online applications, websites and e-shops. Different WCMSs such as WordPress, Drupal and Joomla perform differently in terms of their functionality [15]; thus there are several issues to take into account when selecting a CMS during the website development process [16,17].

The main advantage provided by WCMSs is that they offer users with poor IT background the possibility to create a website [18]. They provide a series of tools and libraries, known as plugins and modules, that enable the user to easily and quickly develop a web application [19]. However, issues around security often encountered by users is one of the disadvantages that stem from using open source WCMSs [20-22]. Annual research conducted by Sucuri indicates that $94 \%$ of hacked websites use WordPress CMS [23]. Several of the security issues are related to the use of not updated plugins [24].

In terms of their popularity, research around a sample of the top 10 million websites available on the Alexa list, indicated that $61 \%$ of websites use some CMS [25]. To be more specific, according to the aforementioned research, 39\% out of the website total does not use a CMS or use a custom one, $38 \%$ relies on WordPress, $2,2 \%$ relies on Joomla and $1,5 \%$ relies on Drupal. Figure 1 also displays the option for Other CMS \& e-business platforms which include electronic commerce systems, such as Shopify $(3,1 \%)$, Magento $(0,7 \%)$, Opencart $(0,6 \%)$, Prestashop $(0,5 \%)$; these, however, are outside the scope of the present research and are therefore not presented extensively.

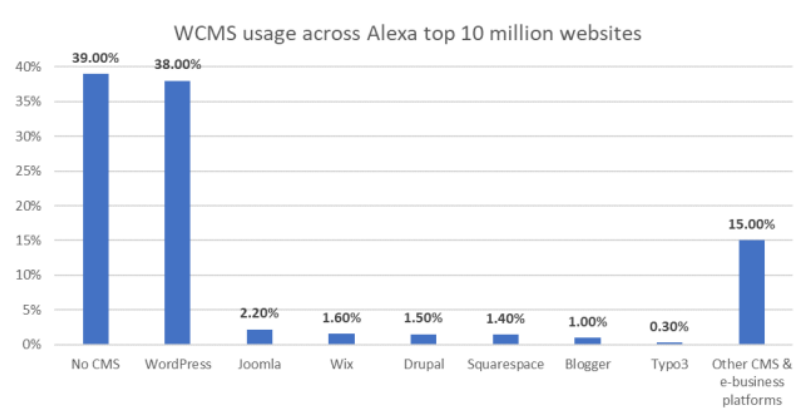

Figure 1. WCMS usage across Alexa top 10 million websites [25]

\subsection{Search Engine Optimization}

There are, therefore, numerous CMSs which enable programmers, digital marketeers, webmasters and others to publish a website online. However, just having a website is not sufficient for business advancement, as its presence amongst search results top rankings is a significant factor in terms of its success. Users utilise search engines on a daily basis in order to search for information around products and services and they mostly select websites that appear at the top five search results of their search [26].

More specifically, industry studies indicate that the top ranking result gets $31,7 \%$ of clicks, the second one gets $24,7 \%$, the third gets $18,7 \%$, the 4 th gets $13,6 \%$ and the 5th gets 9,5\% [27]. Similarly, according to research findings by Sistrix [28] and Moz [29], 71,33\% of searches lead to a website that appears at the top page of organic search results, while the second and third page get 5,59\% of overall clicks. For the first page in particular, the 5 first results get $67,6 \%$ of clicks while results displayed from the $6^{\text {th }}$ until the $10^{\text {th }}$ ranking only get 3,73\%. These statistics highlight the great significance of optimizing websites in terms of search engines, which class websites based on certain criteria. Research suggests that the ranking of a website in SERPs is affected by several factors including on-page factors, off-page factors as well as the key words analysis process $[9,30$ 32].

One of the on-page factors that have proven to affect ranking in search results is Page Size and Website Loading Time $[33,34]$. Website Loading Time is primarily determined by website technology and CMS as well as the webserver where it is hosted, and its optimization is a big challenge for web developers [35]. Responsive design that is related to the website theme and its technology, and therefore to its CMS, is another factor that search engines take into consideration when ranking websites in their SERPs [36]. Furthermore, consistent use of key phrases in 
HTML tags and URLs in landing pages as well as the existence of HTML structured data is also important $[37,38]$. Other research highlights that the use of meta tags is the most significant SEO factor, followed by keywords and website design [39]. Overall it is highlighted that the structure of the website plays an important role for SEO [40].

Applying and optimizing these features during the development or operating process of the website is determined by the ease of use of the WCMS; the average user can easily and quickly make the necessary adaptations to HTML, for instance, when publishing a new article on a website. The same is true for the alternative description (Alt attribute) in the images that are published on a website [41]. CMSs, such as WordPress, Joomla and Drupal have plugins which enable administrators to easily implement SEO techniques, such as the Yoast SEO plugin for WordPress [42]. Facilitating implementation of some characteristics that determine certain on-page factors is directly affected by the website technology and therefore by the WCMS that it uses [43]. These functions appear to be more effective in the case of WordPress due to it being easily manageable, compared to Drupal for example that is more complexly constructed [44]. In a recent commercial study among 10.000 keywords within the automotive sector, websites that do not use any WCMS most frequently appear at the top ranking Google search results, while websites that rely on WordPress follow [45].

Of course, these are just a few of the factors that search engines take into account in order to rank web pages in the SERPs. Further on-page factors, such as the origin and stability of the webserver that hosts the website and the use of caching methods play an important role in SEO. The same applies to off-page factors, such as the quality of backlinks and therefore it is not possible to ascertain which is the friendliest search engine CMS.

\section{Methodology}

In order to record the WCMSs used by experts in the field, SEO experts around the world as well as to investigate the research question of an existing relationship between the top-ranking search results and the utilized WCMS, the authors conducted the following research in two stages within the time period from the $5^{\text {th }}$ until the $20^{\text {th }}$ October 2020 .

It ought to be noted that this research focused on presenting the CMSs used by SEO experts' websites that appear at the top-ranking results. The current analysis documented how well websites are ranked, regardless of whether this is attributed to the used CMS itself or to the successful off-page and on-page factors implementation by the web developers.

The authors selected SEO experts' websites, as they considered that the latter incorporate the majority of other technical SEO factors in their corporate websites, without this being examined in the current research.

During the first stage, the researchers recorded the 40 top-ranking results presented by Google for 180 different search queries. The key phrases that were selected in order to be checked were around user searches for SEO experts in the 90 largest cities in Europe and similarly the 90 largest in the USA ("SEO in Berlin", "SEO in London", "SEO in Paris", "SEO in Athens", "SEO in New York City", "SEO in Chicago", etc.).

Moreover, the regional definition of each city was added in the search queries in order not to activate the Google location algorithm which presents results that are in close proximity to the geographical position of the user that is conducting the search. A relevant table with a full list of key phrases is displayed in the Appendix. Therefore, the research tool REST API provided by apify.com and makes use of Google Search API was used in order to scrape the search results from the 180 different search queries. The Google Search API parameters that were utilized throughout the searches in this tool are the following:

Search query device: Desktop; Search query type: Search; Search query domain: google.com; Country code: AU (Australia), Language: English, Results per page: 20, Pages per query: 2

The results contained the top 40 ranking search results for each of the 180 key phrases used. By omitting the double entries, results came up to a total of 6682 unique website URLs.

In the second stage the authors checked whether these webpages used any of the known WCMSs, such as WordPress, Joomla, Drupal etc. In order to achieve this, the API of whatcms.org was used, through searching for indicators like HTML tags, directory structures, asset files and javascript code in the html markup and headers. Every CMS generates tags or variables in the HTML code which are representative for each of those. The researchers used the CMS detection tool to check the websites for almost 863 different WCMS. The WCMS list for which the websites were checked can be found here https://whatcms.org/Technologies/CMS. It is noted that since these are normal websites and not ecommerce platforms or e-shops, no online applications developed by e-commerce systems 
such as OpenCart, Magento etc. were identified in the sample.

\section{Findings}

In the total of 6682 websites that appeared in the top 40 rankings of search results for the 180 search queries that were analyzed, 32,81\% (2185) did not use any known CMS or used a custom developed CMS. The vast majority $53,56 \%$ (3567) of websites relied on the WordPress system, while $4,08 \%$ (272) relied on Drupal. Just 1,23\% (82) used Joomla, while $8,65 \%$ (576) incorporated other WCMSs on a smaller scale.

The figure displayed below presents the types of WCMS used in websites categorized according to search result rankings (ranks 1-5; ranks 6-10; ranks 11-20; ranks 21-30; ranks 31-40).

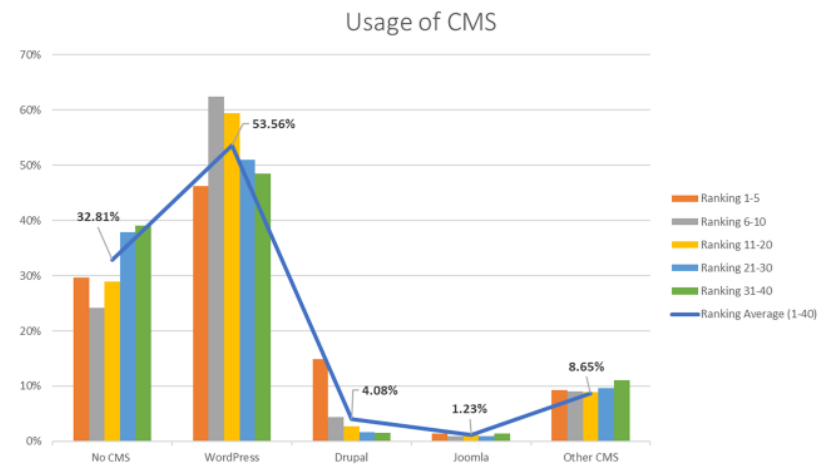

Figure 2. Type of web technology used in websites ranked 1-40 in SERPs for 180 unique search queries

The findings regarding the top 3 search results rankings are particularly interesting as shown in Figure 3, as websites which did not use any wellknown CMS appeared in these rankings more frequently. Websites that used WordPress appeared after these, followed by those that used Drupal. From the $4^{\text {th }}$ ranking onwards the number of websites using WordPress increased and it reached the mean score of the overall sample.

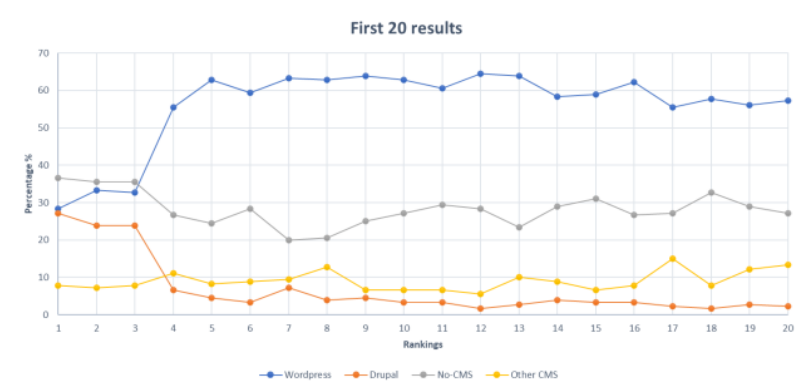

Figure 3. Website technology distribution in 20 top rankings
More specifically, websites that did not use any of the available CMS $(42,23 \%)$ appeared more frequently at the top ranking for search results; $5,56 \%$ of websites that did not use any CMS but have been developed using the Laravel $(1,66 \%)$ and Django framework $(0,64 \%)$ were included within this percentage. The second most frequently used CMS ranking at the first search result was WordPress $(28,33 \%)$. WordPress success rates were almost half compared to the overall sample where WordPress was used by $53,56 \%$ of websites. Websites that used Drupal appeared at the top ranking with great success $(27,22 \%)$, even though Drupal was overall used by just $4,08 \%$ of websites. This was a clear indication that websites which appear at the top rankings for search results predominantly did not use any CMS and secondly, they were created with Drupal to a much greater extent compared to those which were created with WordPress. Similar findings regarding Drupal effectiveness also emerged from presenting the search results ranked second. Moreover, Google Sites appeared at the top rankings at $0,56 \%$ despite the overall Google Sites percentage in the sample being $0,47 \%$. With regards to Joomla, it appeared at the top rankings at $0,56 \%$ while its overall percentage in the sample is $1,23 \%$.

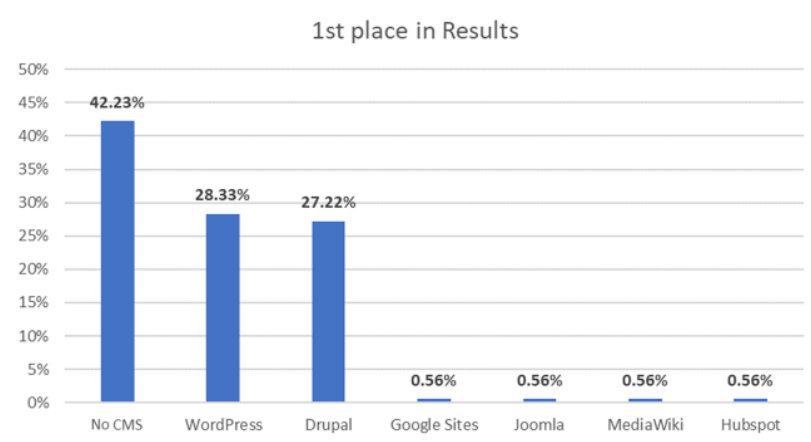

Figure 4. Technology used in $1^{\text {st }}$ ranking websites

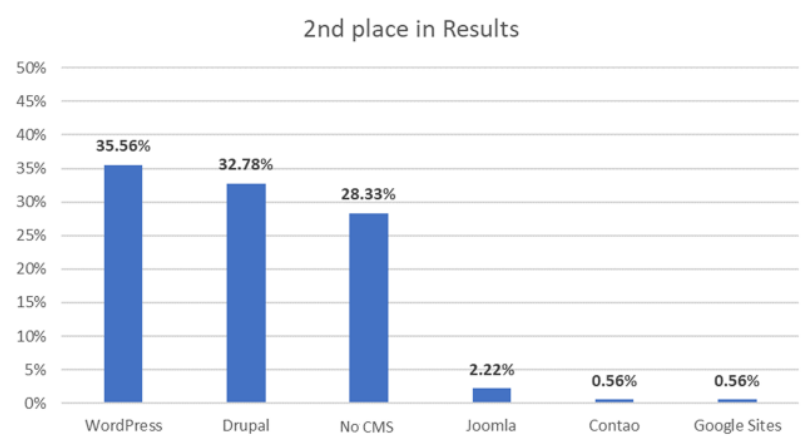

Figure 5. Technology used in $2^{\text {nd }}$ ranking websites

With regards to search results for the third ranking, the vast majority of websites belonged to the following categories: WordPress at $51,11 \%$, 'No CMS' at $32,33 \%$ and Drupal at $12,22 \%$. 
Regarding search results for the fourth ranking in SEPRs, statistical findings started to follow along the mean scores of the overall sample: WordPress occupied the top ranking at $55,56 \%$, followed by the website percentage that did not use any WCMS $(33,34 \%)$ and the next ranking was occupied by Drupal at $6,67 \%$. It is worth noting that websites that have been developed through using Google Sites appeared to maintain their percentages at the top 4 rankings for search results.

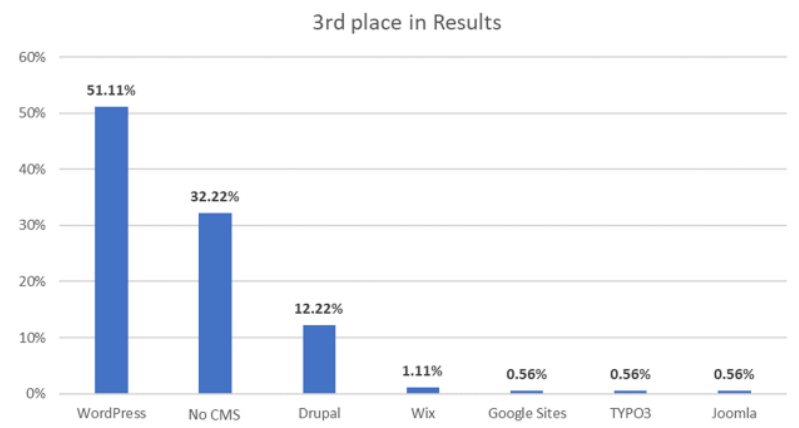

Figure 6. Technology used in 3rd ranking websites

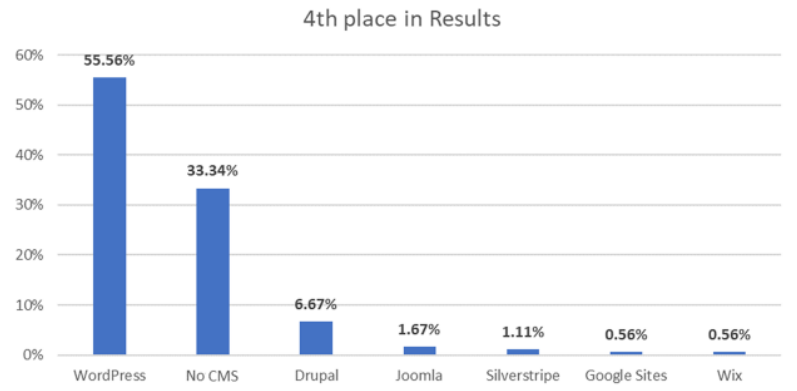

Figure 7. Technology used in $4^{\text {th }}$ ranking websites

The following figures present a comparison between WordPress and websites that did not use any well-known CMS (Figure 8) and WordPress and Drupal (Figure 9). It is evident that websites that did not use any WCMS maintained a better percentage in terms of appearing at the top 3 rankings for search results, while Drupal was ranked quite positively at the top 3 rankings for search results which are the most significant ones as they gather $31,7 \%, 24,7 \%$ and $18,7 \%$ of clicks for organic search results respectively [27].

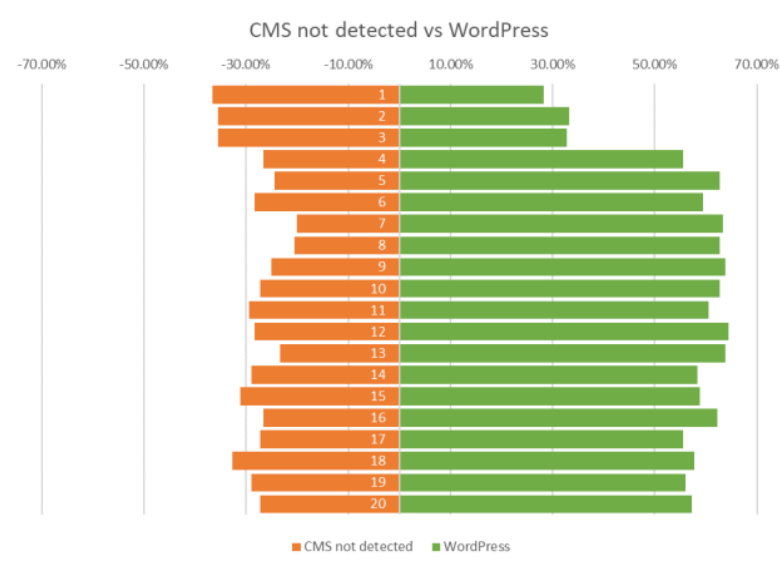

Figure 8. Pyramid diagram No CMS vs WordPress

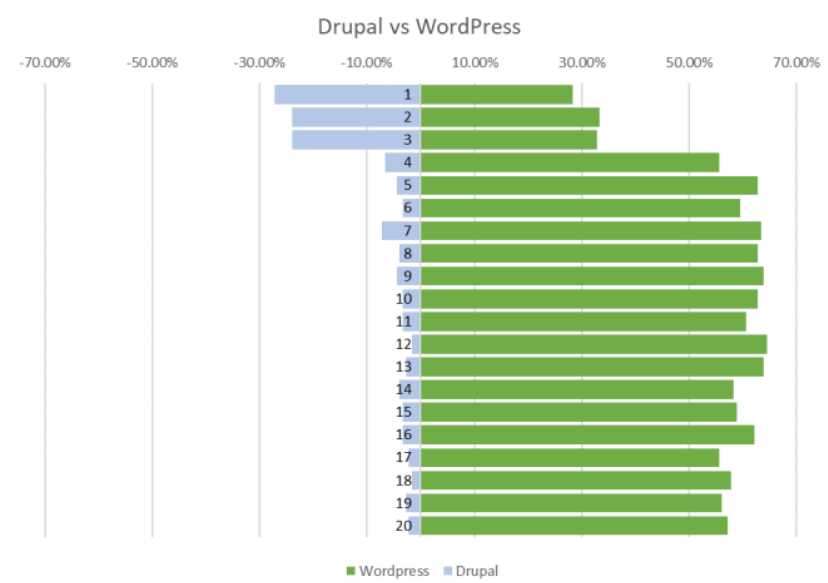

Figure 9. Pyramid diagram Drupal vs WordPress

\section{Discussion}

The present research highlighted that SEO experts showed a higher preference in terms of using WordPress and Drupal as they used these at $53,56 \%$ and $4,08 \%$ respectively, when the mean score in terms of their use based on the research conducted by w3techs.com is $38,8 \%$ and $1,5 \%$ (CMS Technologies Web Usage Distribution, 2020) and by whatcms.org $30,28 \%$ and $1,45 \%$ [46] respectively. Furthermore, the current research conducted amongst 6682 search results indicated that websites which have not been developed by using any of the available WCMSs appeared more frequently at top rankings of search results. Gotch's research which was conducted amongst 10.000 keywords within the automotive sector also reached the same conclusions regarding websites that did not use any WCMS and appeared at the top ranking in SERPs [45]. This could be interpreted by the fact that websites that are constructed in custom ways use significantly less coding and have faster loading speed compared to a website which relies on a WCMS and is not SEO optimized.

At the same time, Drupal was evaluated positively, maintaining significantly high percentages at the 
top 3 rankings for the search results in the present research. Increased Drupal use by SEO experts could also be interpreted by the fact that Drupal requires more specialized knowledge that the average user may not possess. After all Drupal use percentages appeared to be much lower within the automotive sector, as highlighted by Gotch's research.

Furthermore, WordPress, which according to this research, was used by the majority of SEO experts' websites $(53,56 \%)$ did not respectively maintain the same high percentages at the top two rankings for search results, as Drupal does. The fact that WordPress was not highly frequently encountered at the top rankings for search results could also be explained by the fact that many plugins from third party creators were not optimized and may cause problems in terms of website loading times and user experience perspective [47]. Apart from WordPress, Drupal and Joomla, other CMS which appeared at the top 4 rankings for search results in the current research were Contao, Google Sites, MediaWiki, HubSpot, TYPO3 and Wix; however, their percentages in the overall sample were too low in order to reach any conclusions.

\section{Conclusions}

The initial aim was to study which WCMSs are utilized by SEO experts as well as to examine whether the use of a specific CMS positively affects ranking for Google search results.

Research was conducted amongst 6882 websites that appeared at the top 40 rankings for search results by searching for SEO experts' websites worldwide. The authors observed that websites which do not use any WCMS appeared more frequently at the top ranking which is the most significant one since it gets the highest number of users' clicks. Websites that used WordPress appeared next, while the Drupal percentage was unexpectedly high, despite Drupal being used by a very low online percentage overall. From the fifth ranking downwards, a regularity was noted in terms of results with WordPress occupying the top ranking and maintaining steady percentages up until the 40th ranking for search results.

This lack of homogeneity for the top 5 rankings was indicative of an association between the top rankings for search results and the WCMS that was used. Confirmation for this observation should be reached through further research that would take additional SEO criteria into account, since the range of relevant research is still limited.

However, the main finding which highlighted that the top-ranking websites did not use any WCMS, does not necessarily mean that WCMSs such as WordPress or Joomla are not search engine friendly. In line with this, WMCS are tools used by web developers in order to create a website, while SEO also depends on a plethora of other factors and actions that are implemented at a later stage. Therefore, this constituted a significant limitation for the present research.

Further research regarding loading times for the examined websites as well as the use of an updated CMS would be able to highlight the ways in which the website's loading time factor and any potential security issues can affect the rankings in SERPs. Moreover, a pilot study could also be used in ecommerce sites in order to investigate any potential differentiations that may arise or to conduct the same research by replicating it through using other search engines, such as Bing and Yandex. Finally, the study could also be conducted in other fields besides SEO experts in order to identify any differences. This is a field that has not been extensively researched; it appears to be quite interesting both in terms of developers and in terms of website owners, as they aim to optimize their websites in the search results as well as to gain significant advantages over their competitors.

\section{References}

[1]. Giomelakis, D.; Veglis, A.A. Search Engine Optimization Available online: www.igi-global.com/chapter/searchengine-optimization/214740 (accessed on 8 January 2021).

[2]. Domenech, J.; Rizov, M.; Vecchi, M. The Impact of Companies' Websites on Competitiveness and Productivity Performance. In Proceedings of the Conference Paper: First International Conference on Advanced Research Methods and Analytics; 2015.

[3]. Egri, G.; Bayrak, C. The Role of Search Engine Optimization on Keeping the User on the Site. Procedia Computer Science 2014, 36, 335-342, doi:10.1016/j.procs.2014.09.102.

[4]. Iskandar, M.S.; Komara, D. Application Marketing Strategy Search Engine Optimization (SEO). IOP Conf. Ser.: Mater. Sci. Eng. 2018, 407, 012011, doi:10.1088/1757-899X/407/1/012011.

[5]. Tomasi, S.; Li, X. Influences of Search Engine Optimization on Performance of SMEs: A Qualitative Perceptive Available online: www.igiglobal.com/chapter/influences-of-searchengine-optimization-on-performance-of- 
smes/195154 (accessed on 8 January 2021).

[6]. Malaga, R.A. The Value of Search Engine Optimization: An Action Research Project at a New E-Commerce Site Available online: www.igi-global.com/article/valuesearch-engine-optimization/3498

(accessed on 8 January 2021).

[7]. Search Engine Market Share Worldwide Available online: https://gs.statcounter.com/search-enginemarket-share (accessed on 29 October 2020).

[8]. Giomelakis, D.; Veglis, A. Theory and Practice of Search Engine Optimization Available online: www.igiglobal.com/chapter/theory-and-practiceof-search-engine-optimization/263621 (accessed on 8 January 2021).

[9]. Ziakis, C.; Vlachopoulou, M.; Kyrkoudis, T.; Karagkiozidou, M. Important Factors for Improving Google Search Rank. Future Internet 2019, 11, 32.

[10]. CMS Technologies Web Usage Distribution Available online: https://trends.builtwith.com/cms (accessed on 29 October 2020).

[11]. McKeever, S. Understanding Web Content Management Systems: Evolution, Lifecycle and Market. Industrial Management \& Data Systems 2003, 103, 686-692, doi:10.1108/02635570310506106.

[12]. Michelinakis, D. Open Source Content Management Systems: An Argumentative Approach. The University of Warwick: Warwick Manufacturing Group, A report submitted for the award of MSc Electronic Business Management 2004.

[13]. Das, S. A Systematic Study of Integrated Marketing Communication and Content Management System for Millennial Consumers. In Innovations in Digital Branding and Content Marketing; IGI Global, 2020; pp. 91-112.

[14]. Hedgebeth, D. Gaining Competitive Advantage in a Knowledge- based Economy through the Utilization of Open Source Software. VINE 2007, 37, 284-294, doi:10.1108/03055720710825618.

[15]. Patel, S.K.; Rathod, V.R.; Prajapati, J.B. Performance Analysis of Content Management Systems-Joomla,
Drupal and Wordpress. International Journal of Computer Applications 2011, $21,39-43$.

[16]. Al-Hawari, F.; Mai Al-Zu'bi; Barham, H.; Sararhah, W. The GJU Website Development Process and Best Practices Available online: www.igiglobal.com/teaching-case/the-gju-websitedevelopment-process-and-best-

practices/266435 (accessed on 8 January 2021).

[17]. Boateng, B.A.; Boateng, K. Issues to Consider When Choosing Open Source Content Management Systems (CMSs) Available online: www.igiglobal.com/chapter/issues-consider-whenchoosing-open/21193 (accessed on 8 January 2021).

[18]. Ramnath, A. A Methodology for Evaluating Capability, Effort and Ease of Implementation in Modular Web Content Management Systems. Thesis, 2017.

[19]. Priefer, D.; Kneisel, P.; Strüber, D. Iterative Model-Driven Development of Software Extensions for Web Content Management Systems. In Proceedings of the Modelling Foundations and Applications; Anjorin, A., Espinoza, H., Eds.; Springer International Publishing: Cham, 2017; pp. 142-157.

[20]. Erturk, E. Cloud Computing and Cybersecurity Issues Facing Local Enterprises Available online: www.igiglobal.com/chapter/cloud-computing-andcybersecurity-issues-facing-localenterprises/228809 (accessed on 8 January 2021).

[21]. Meike, M.; Sametinger, J.; Wiesauer, A. Security in Open Source Web Content Management Systems. Security \& Privacy, IEEE 2009, 7, 44-51, doi:10.1109/MSP.2009.104.

[22]. Viduka, D.; Kraguljac, V.; Lavrnić, I. Security Challenges Behind the Development and Increased Use of Open Source Web Content Management Systems. Journal of Information and Organizational Sciences 2020, 44, 185198, doi:10.31341/jios.44.1.9.

[23]. Sucuri - Website Threat Report 2019 Available online: https://sucuri.net/reports/2019-hackedwebsite-report/ (accessed on 3 November 2020). 
[24]. Vasek, M.; Wadleigh, J.; Moore, T. Hacking Is Not Random: A CaseControl Study of Webserver-Compromise Risk. IEEE Transactions on Dependable and Secure Computing 2016, 13, 206-219, doi:10.1109/TDSC.2015.2427847.

[25]. Usage Statistics and Market Share of Content Management Systems, October 2020 Available online: https://w3techs.com/technologies/overvie w/content management (accessed on 29 October 2020).

[26]. Keane, M.T.; O’Brien, M.; Smyth, B. Are People Biased in Their Use of Search Engines? Commun. ACM 2008, 51, 49-52, doi:10.1145/1314215.1314224.

[27]. Dean, B. We Analyzed 5 Million Google Search Results. Here's What We Learned About Organic CTR Available online: https://backlinko.com/google-ctrstats (accessed on 3 November 2020).

[28]. Beus, J. Why (Almost) Everything You Knew about Google CTR Is No Longer Valid. SISTRIX 2020.

[29]. Petrescu, P. Google Organic Click-Through Rates in 2014 Available online: https://moz.com/blog/googleorganic-click-through-rates-in-2014 (accessed on 3 November 2020).

[30]. Lopezosa, C.; Codina, L.; Gonzalo-Penela, C. Off-page SEO and link building: General strategies and authority transfer in the digital news media. El profesional de la información (EPI) 2019 , 28 , doi:10.3145/epi.2019.ene.07.

[31]. Zhu, X.; Tan, Z. SEO Keyword Analysis and Its Application in Website Editing System. In Proceedings of the 2012 8th International Conference on Wireless Communications, Networking and Mobile Computing; September 2012; pp. 1-4.

[32]. Schultheiß, S.; Lewandowski, D. "Outside the Industry, Nobody Knows What We Do" SEO as Seen by Search Engine Optimizers and Content Providers. Journal of Documentation 2020, 77, 542557, doi:10.1108/JD-07-2020-0127.

[33]. Krriztiann, V.S. On-Page SEO: How to Make Google Fall in Love with Your Website Google Marketing Strategies and Tricks; Independently published, 2018; ISBN 978-1-983226-68-7.
[34]. Özkan, B.; Özceylan, E.; Kabak, M.; Dağdeviren, M. Evaluating the Websites of Academic Departments through SEO Criteria: A Hesitant Fuzzy Linguistic MCDM Approach. Artif Intell Rev 2020, 53, 875-905, doi:10.1007/s10462-019-09681-z.

[35]. Manhas, J. A Study of Factors Affecting Websites Page Loading Speed for Efficient Web Performance. International Journal of Computer Sciences and Engineering 2013, 1, 32-35.

[36]. Yadav, P.; Barwal, P.N. Designing Responsive Websites Using HTML And CSS; 2014;

[37]. Matošević, G. Measuring the Utilization of On-Page Search Engine Optimization in Selected Domain. Journal of Information and Organizational Sciences 2015, 39, 199-207.

[38]. Scott, D. White Hat Search Engine Optimization (SEO): Structured Web Data for Libraries. 2015.

[39]. Tsuei, H.J.; Tsai, W.H.; Pan, F.T.; Tzeng, G.H. Improving Search Engine Optimization (SEO) by Using Hybrid Modified MCDM Models. Artificial Intelligence Review 2020, 53, undefinedundefined, doi:10.1007/s10462-018-96440.

[40]. Barbar, A.; Ismail, A. Search Engine Optimization (SEO) for Websites. ACM International Conference Proceeding Series 2019, Part F148262, 51-55, doi:10.1145/3323933.3324072.

[41]. Ferraz, R. Accessibility and Search Engine Optimization on Scalable Vector Graphics. In Proceedings of the 2017 IEEE 4th International Conference on Soft Computing Machine Intelligence (ISCMI); November 2017; pp. 94-98.

[42]. Bergström, S. SEO for Web Developers : $\quad$ Understanding, Implementing \&amp;Amp; Testing; 2020;

[43]. Qiu, Y. CMS Website Search Engine Optimization: Case Study: EuropeInternship. Com. 2014.

[44]. Martinez-Caro, J.-M.; AledoHernandez, A.-J.; Guillen-Perez, A.; Sanchez-Iborra, R.; Cano, M.-D. A Comparative Study of Web Content Management Systems. Information 2018, 9, 27, doi:10.3390/info9020027.

[45]. Gotch, N. What's the Best CMS for SEO in 2020? (Data-Driven Answer) 
Available

https://www.gotchseo.com/best-cms-for-

$\mathrm{seo} /$ (accessed on 27 November 2020).

[46]. Tech Reports - What CMS?

Available

https://whatcms.org/Tech_Reports

(accessed on 8 January 2021).

[47]. WP, B. How WordPress Plugins Affect Your Site's Load Time Available online: https://www.wpbeginner.com/wptutorials/how-wordpress-plugins-affectyour-sites-load-time/ (accessed on 24 February 2021).

online:

\begin{abstract}
This research received no specific grant from any funding agency in the public, commercial, or notfor-profit sectors.
\end{abstract}

\section{Contribution of individual authors}

Conceptualization and formal analysis: C.Z.; investigation and methodology: C.Z. and M.V.; writing - original draft preparation: C.Z.; review and editing: M.V. The authors have read and agreed to the published version of the manuscript.

\section{Creative Commons Attribution License 4.0 (Attribution 4.0 International, CC BY 4.0)}

This article is published under the terms of the Creative Commons Attribution License 4.0

https://creativecommons.org/licenses/by/4.0/deed.en_US 


\section{Appendix}

Table 1. List of search queries used

\begin{tabular}{|c|c|}
\hline & \\
\hline & SEO in Madrid \\
\hline & SEO in Rome \\
\hline & SEO in Bucharest \\
\hline & SEO in Paris \\
\hline & SEO in Vienna \\
\hline & SEO in Hamburg \\
\hline & SEO in Warsaw \\
\hline & SEO in Budapest \\
\hline & SEO in Barcelona \\
\hline & SEO in Munich \\
\hline & SEO in Milan \\
\hline & SEO in Prague \\
\hline & SEO \\
\hline & SEO in Cologne \\
\hline & SEO in Stockholm \\
\hline & SEO in Naples \\
\hline & SEO in Turin \\
\hline & SEO in Amsterdam \\
\hline & SEO in Marseille \\
\hline & SEO in Zagreb \\
\hline & SEO in Copenhage \\
\hline & SEO in Valencia \\
\hline & SEO in Krakow \\
\hline & SEO in Frankfurt \\
\hline & SEO in Seville \\
\hline & SEO in Lodz \\
\hline & SEO in Zaragoza \\
\hline & SEO in Athens \\
\hline & SEO in Palermo \\
\hline & SEO in Rotterdam \\
\hline & SEO in Helsinki \\
\hline & SEO in Wroclaw \\
\hline & SEO in Stuttgart \\
\hline & SEO in Riga \\
\hline & SEO in Düsseldorf \\
\hline & SEO in Leipzig \\
\hline & SEO in Dortmund \\
\hline & SEO in Essen \\
\hline & SEO in Gothenbur \\
\hline & SEO in Genoa \\
\hline & SEO in Malaga \\
\hline & SEO in Bremen \\
\hline & SEO in Vilnius \\
\hline & \\
\hline
\end{tabular}

46. SEO in Dublin

47. SEO in Hague

48. SEO in Hanover

49. SEO in Poznan

50. SEO in Antwerp

51. SEO in Nuremberg

52. SEO in Lyon

53. SEO in Lisbon

54. SEO in Duisburg

55. SEO in Toulouse

56. SEO in Gdansk

57. SEO in Murcia

58. SEO in Tallinn

59. SEO in Bratislava

60. SEO in Palma de Mallorca

61. SEO in Szczecin

62. SEO in Bologna

63. SEO in Brno

64. SEO in Iasi

65. SEO in Florence

66. SEO in Las Palmas

67. SEO in Bochum

68. SEO in Utrecht

69. SEO in Wuppertal

70. SEO in Aarhus

71. SEO in Bydgoszcz

72. SEO in Plovdiv

73. SEO in Bilbao

74. SEO in Malmo

75. SEO in Nice

76. SEO in Lublin

77. SEO in Varna

78. SEO in Bielefeld

79. SEO in Alicante

80. SEO in Timisoara

81. SEO in Bonn

82. SEO in Cordoba

83. SEO in Thessaloniki

84. SEO in Cluj-Napoca

85. SEO in Bari

86. SEO in Constanta

87. SEO in Munster

88. SEO in Karlsruhe

89. SEO in Catania

90. SEO in Mannheim
91. SEO in New York City

92. SEO in Los Angeles

93. SEO in Chicago

94. SEO in Houston

95. SEO in Phoenix

96. SEO in Philadelphia

97. SEO in San Antonio

98. SEO in San Diego

99. SEO in Dallas

100. SEO in San Jose

101. SEO in Austin

102. SEO in Jacksonville

103. SEO in Fort Worth

104. SEO in Columbus

105. SEO in Charlotte

106. SEO in San Francisco

107. SEO in Indianapolis

108. SEO in Seattle

109. SEO in Denver

110. SEO in Washington

111. SEO in Boston

112. SEO in El Paso

113. SEO in Nashville

114. SEO in Detroit

115. SEO in Oklahoma City

116. SEO in Portland

117. SEO in Las Vegas

118. SEO in Memphis

119. SEO in Louisville

120. SEO in Baltimore

121. SEO in Milwaukee

122. SEO in Albuquerque

123. SEO in Tucson

124. SEO in Fresno

125. SEO in Mesa

126. SEO in Sacramento

127. SEO in Atlanta

128. SEO in Kansas City

129. SEO in Colorado Springs

130. SEO in Omaha

131. SEO in Raleigh

132. SEO in Miami

133. SEO in Long Beach

134. SEO in Virginia Beach

135. SEO in Oakland
136. SEO in Minneapolis

137. SEO in Tulsa

138. SEO in Tampa

139. SEO in Arlington

140. SEO in New Orleans

141. SEO in Wichita

142. SEO in Bakersfield

143. SEO in Cleveland

144. SEO in Aurora

145. SEO in Anaheim

146. SEO in Honolulu

147. SEO in Santa Ana

148. SEO in Riverside

149. SEO in Corpus Christi

150. SEO in Lexington

151. SEO in Henderson

152. SEO in Stockton

153. SEO in Saint Paul

154. SEO in Cincinnati

155. SEO in St. Louis

156. SEO in Pittsburgh

157. SEO in Greensboro

158. SEO in Lincoln

159. SEO in Anchorage

160. SEO in Plano

161. SEO in Orlando

162. SEO in Irvine

163. SEO in Newark

164. SEO in Durham

165. SEO in Chula Vista

166. SEO in Toledo

167. SEO in Fort Wayne

168. SEO in St. Petersburg

169. SEO in Laredo

170. SEO in Jersey City

171. SEO in Chandler

172. SEO in Madison

173. SEO in Lubbock

174. SEO in Scottsdale

175. SEO in Reno

176. SEO in Buffalo

177. SEO in Gilbert

178. SEO in Glendale

179. SEO in North Las Vegas

180. SEO in Winston-Salem 